\section{Einfach geht auch}

G roß ist der Büchermarkt für uns Allergologen geworden, und groß und umfangreich sind auch die Werke, die wir als Allergologen zu unserer Fortbildung selbst lesen sollten. Ebenso ist das Angebot an Informationen für den Allergiker fast unüberschaubar geworden. Und da kommt ein kleines gelbes Buch mit einer sich duschenden Katze auf der Vorderseite daher und ist damit offenbar auch noch sehr erfolgreich.

Die Rede ist von dem heitersten und fröhlichsten Buch über die Basics der klinischen Allergologie von Dr. rer. nat. Rüdiger Wahl aus Hamburg, das in diesen Tagen in seiner inzwischen sechsten Auflage erscheint.

Das Buch, primär für interessierte allergiekranke Patienten geschrieben und doch in gleicher Weise auch für Ärzte außerordentlich bildend, vermittelt in heiterer und fröhlicher Weise auf 170 Seiten die wichtigsten Informationen über allergische Erkrankungen, ihre Ursachen, die Diagnostik sowie Prävention und Therapie. Dabei werden keine Oberflächlichkeiten mitgeteilt, sondern die wesentlichen Fakten vermittelt, die heute als gesichertes Wissen angesehen werden. Fantasiereiche Abbildungen, prägnante Erzählungen von Einzelschicksalen und auch ein Einstieg in die musikalische Welt der Allergien werden geboten.

Fazit: Dieses Buch ist sehr zu empfehlen zum eigenen Lesen und es ist ein wunderbares Geschenk für befreundete Allergiker oder humorbegabte andere Allergologen.

Prof. Dr. Karl-Christian Bergmann, Bad Lippspringe

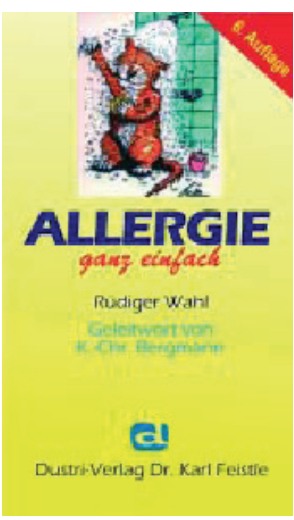

Wahl R.

Allergie - ganz einfach.

Deisenhofen: Dustri,

2003 (6. Auflage).

$12,90 €$.

ISBN: 3-87185-339-9

\begin{tabular}{|c|c|c|c|c|}
\hline Platz & Autor & Titel & Verlag & Preis \\
\hline 1 & Jäger, Wüthrich & $\begin{array}{l}\text { Nahrungsmittelallergien } \\
\text { und -intoleranzen }\end{array}$ & Urban \& Fischer & $59,95 €$ \\
\hline 2 & Illing & Lightfaden Allergien & Urban \& Fischer & $14,95 €$ \\
\hline 3 & Heppt, Renz, Röcken & Allergologie & Springer & $94,95 €$ \\
\hline 4 & Abeck & $\begin{array}{l}\text { Atopisches Ekzem im } \\
\text { Kindesalter }\end{array}$ & Steinkopff & $54,95 €$ \\
\hline 5 & $\begin{array}{l}\text { Przybilla, Bergmann, } \\
\text { Ring }\end{array}$ & $\begin{array}{l}\text { Praktische allergologische } \\
\text { Diagnostik }\end{array}$ & Steinkopff & $99,95 €$ \\
\hline 6 & Reinhardt & $\begin{array}{l}\text { Asthma bronchiale im } \\
\text { Kindesalter }\end{array}$ & Springer & $44,95 €$ \\
\hline 7 & Zollner & Atopische Dermatitis & Blackwell & $64,95 €$ \\
\hline 8 & $\begin{array}{l}\text { Altmeyer, } \\
\text { Bacharach-Buhles }\end{array}$ & $\begin{array}{l}\text { Dermatologie, Allergologie, } \\
\text { Umweltmedizin }\end{array}$ & Springer & $199,00 €$ \\
\hline 9 & Dott, Merk, Neuser & $\begin{array}{l}\text { Lehrbuch der } \\
\text { Umweltmedizin }\end{array}$ & WVG & $118,00 €$ \\
\hline 10 & Böse-O'Reilly & Leitfaden Umweltmedizin & Urban \& Fischer & $59,95 €$ \\
\hline
\end{tabular}

\title{
Urlaubstipps für Allergiker
}

$\mathrm{D}$

amit die Reiseerlebnisse sich bei Allergikern nicht in Krankheitsberichte verwandeln, ist die richtige Unterkunft entscheidend. Hilfreich ist dabei der Katalog „Allegro - Der Service für Allergiker". Im Mittelpunkt dieses einmal pro Jahr erscheinenden Werkes steht ein Tabellenteil, der sich aus der Quartiergeber-Tabelle 2003/04, einer Liste mit Selbsthilfegruppen und dem Einkaufsführer von A-Z zusammensetzt. Die Quartiergeber-Tabelle umfasst eine Sammlung von Allergiker-gerechten Hotels, Ferienquartieren und Kurkliniken im In- und Ausland. Jedes Objekt wird mit Kontaktadresse, Preisangaben und einer kurzen Beschreibung aufgeführt. Außerdem ist eine Reihe von Punkten berücksichtigt, die für Allergiker besonders wichtig sind, wie z. B. die Frage, ob es möglich ist, Diätkost zu bekommen oder ob Luftreinigungsgeräte zum Einsatz kommen. Auch die Adressen von Selbsthilfegruppen und der Einkauffführer bieten Allergikern einen schnellen Überblick. Praktisch ist auch das Online-Äquivalent www.allegroportal.de, das z. B. die UnterkünfteSuchmaschine bietet.
Um den Tabellenteil herum rankt sich ein Geflecht von Beiträgen, unterteilt in die Rubriken Reisen, Gesundheit sowie Bauen und Wohnen, in dem redaktionelle Artikel, Produktinformationen von Unternehmen und Anzeigen recht bunt miteinander vermischt sind. Zwar sind z. B. Produktinformationen durch das kleine Wörtchen „Hintergrund" gekennzeichnet, ob aber der unbedachte Leser diese Hinweise richtig interpretiert, sei dahingestellt.

Erwähnenswert ist, dass von jedem verkauften Heft ein Euro an die Sandra-Völker-Stiftung zugunsten asthmakranker Kinder geht.

mwe

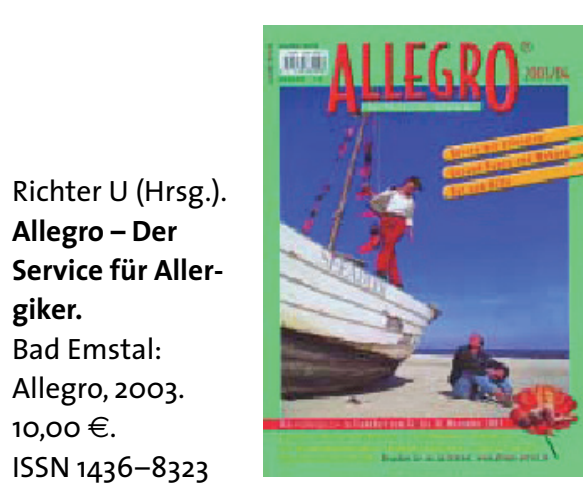

